\title{
Women in science: physics and optics
}

\author{
M. Yzuel, A. Peinado
}

M. J. Yzuel, A. Peinado, "Women in science: physics and optics," Proc. SPIE 9289, 12th Education and Training in Optics and Photonics Conference, 92892X (17 July 2014); doi: 10.1117/12.2070740

SPIE Event: 12th Education and Training in Optics and Photonics Conference, SPIE. 2013, Porto, Portugal 


\title{
Women in Science: Physics and Optics
}

\author{
M. J. Yzuel*a ${ }^{* a}$ A. Peinado ${ }^{\mathrm{a}}$ \\ ${ }^{a}$ Departament de Física, Universitat Autònoma de Barcelona, Bellaterra, 08193, SPAIN
}

\begin{abstract}
The number of women is less than the number of men in degrees like physics and engineering. In this paper we present the percentages of female students at the Spanish Universities. The percentage of women decreases for faculty members. We also give some figures for female students in physics degree. The value of mentoring programs is analyzed. The learning societies in physics and in optics have established committees and programs for helping the women in their scientific career. We describe them in general and we focus on the SPIE Women in Optics program.
\end{abstract}

Keywords: Women in science, gender equity, science education.

\section{INTRODUCTION}

The low number of women in the fields of physics and engineering has been discussed in several conferences and in some papers. The analysis is generally done by giving the number and percentage of female students as well as the percentages of women who have developed a scientific career. Sociological studies may help to understand better the reasons that produce this gender gap.

The knowledge based on education is an important factor to define the degree of social and economic development of the society. So the access of women to high degree education, starting in some countries at the end of the XIX century, but more generally along the XX century, is an important step in this direction. Now, in many countries, the number of female students at the universities is slightly higher than the number of male students.

In a long and general study in US [1], Linda Sax compares women's and men's development during the undergraduate years with a documented analysis that identifies many ways that college impacts men and women differently. From the data obtained from a sample of 17000 male and female students that represent 200 institutions in US, Sax examines the impact of college experiences, peer groups, and faculty on a comprehensive array of student outcomes. This documented study suggests that women and men are not affected in the same way by the undergraduate experience.

The European Commission has released in April 2013 the document "She figures 2012" [2]. This document is published every three years and provides a wealth of data on the gender breakdown at different levels, and in different sectors, within research and innovation.

The International Union of Pure and Applied Physics organizes an International Conference on Women in Physics every three years. The first Conference was in Paris in 2002 and the second one in Rio de Janeiro in 2005 [3,4]. The most recent conference was held in 2011. In the two first conferences two surveys were carried out with participation of more than 1000 women from 50 countries. The third survey, the Global Survey of Physicists [5,6], was sent to men as well as women to document the differences between their experiences. It reached 15000 physicists from 130 countries and the answers arrived by October 2010. The surveys try to ascertain working relationship in graduate schools and laboratories, access to opportunities and resources, and the effects of those variables on women's careers. In the third survey another important variable was added: family obligations. Ivie and Tesfaye [7] point out that the low representation of women in physics is a problem the community needs to address, but the community also needs to address inequities in access to resources and opportunities. Other factors like cultural expectations about home and family that may inhibit the progress of women physicists are more difficult to change.

The group of Women in Physics from the Spanish Royal Physical Society has participated in the four International Conferences on Women in Physics organized by IUPAP. The last paper about the status in Spain can be read in [8].

*Maria.Yzuel@uab.es; phone +34935811933;

12th Education and Training in Optics and Photonics Conference, edited by

Manuel F. P. C. Martins Costa, Mourad Zghal, Proc. of SPIE Vol. 9289, 92892X

(C) 2014 SPIE, OSA, IEEE, ICO · doi: 10.1117/12.2070740

Proc. of SPIE Vol. 9289 92892X-1 
In this paper, we will present in section 2 numbers of students and percentages of women in the Spanish Universities. We will compare the percentage of women in physics degree with the percentage of female students in general. The percentages of professors at the universities are studied in section 2.1.2. In section 3, we will analyze the advantages that the mentoring programs can provide for the recruitment and retention of female graduate and Ph.D. students in a scientific career. Finally, we present in section 4 some projects developed by scientific professional societies in physics and in optics. We focus on the SPIE programs in Women in Optics.

\section{CURRENT SITUATION IN THE SPANISH UNIVERSITIES}

\subsection{General statistical data}

In this section we present some relevant information about the current situation of women in the Spanish universities. The tables and graphs showed below have been extracted from the comprehensive analysis conducted by the Spanish Ministry of Education in the year 2012 [9] with statistical data from all Spanish universities. First, we focus on the students distribution and then, on the professors.

\subsubsection{Students}

The percentages of women over the total registered and graduated students in Spanish universities are shown in Table. 1. The unification of the new European studies has led Spain to the creation of new programs adapted to European Higher Education Area (EHEA) [10]. This unification has not been made simultaneously in all universities. Thus, currently in the universities, there are coexisting undergraduate students in the current program (EHEA) and in the previous program. We observe that concerning registered students, women are more than $50 \%$ in all different levels of studies (undergraduate and Master studies).

Table 1. Registered and graduated students in the university system, 2011-12.

\begin{tabular}{|c|c|c|c|c|}
\cline { 2 - 5 } \multicolumn{1}{c|}{} & \multicolumn{2}{c|}{ Registered } & \multicolumn{2}{c|}{ Graduated } \\
\cline { 2 - 5 } \multicolumn{1}{c|}{} & Total & \% of women & Total & \% of women \\
\hline Total students & $\mathbf{1 . 5 8 2 . 7 1 4}$ & $\mathbf{5 4 , 3 \%}$ & $\mathbf{2 6 7 . 0 6 9}$ & $\mathbf{5 9 , 1 \%}$ \\
\hline $\begin{array}{c}\text { Undergraduate students in the current } \\
\text { program }\end{array}$ & 824.741 & $55,4 \%$ & 20.743 & $46,0 \%$ \\
\hline $\begin{array}{c}\text { Undergraduate students in the previous } \\
\text { program }\end{array}$ & 644.912 & $52,7 \%$ & 196.497 & $61,1 \%$ \\
\hline Master students & 113.061 & $54,6 \%$ & 49.829 & $56,9 \%$ \\
\hline
\end{tabular}

The percentage of undergraduate students divided by gender and education fields is represented in Fig.1. We observe that the lowest percentage of female students is in engineering and architecture, whereas the highest is in health sciences. The percentage of female students in science is slightly higher than $50 \%$, but it is well known that this percentage changes for each specific major. In particular, in physics is much smaller. We will discuss this case in the section 2.2.



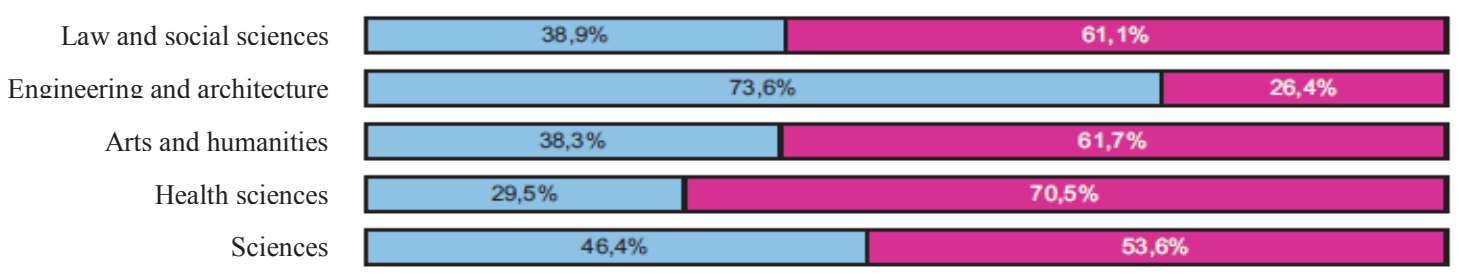

Figure 1. Undergraduate students distribution by education fields and gender, 2011-12. 
The percentages of women in Master degrees, shown in Fig.2, present a similar tendency with respect to undergraduate studies. We see a small decrease of women in Masters in science; while in engineering and architecture, the percentage is slightly higher for Master female students than for undergraduate female students.

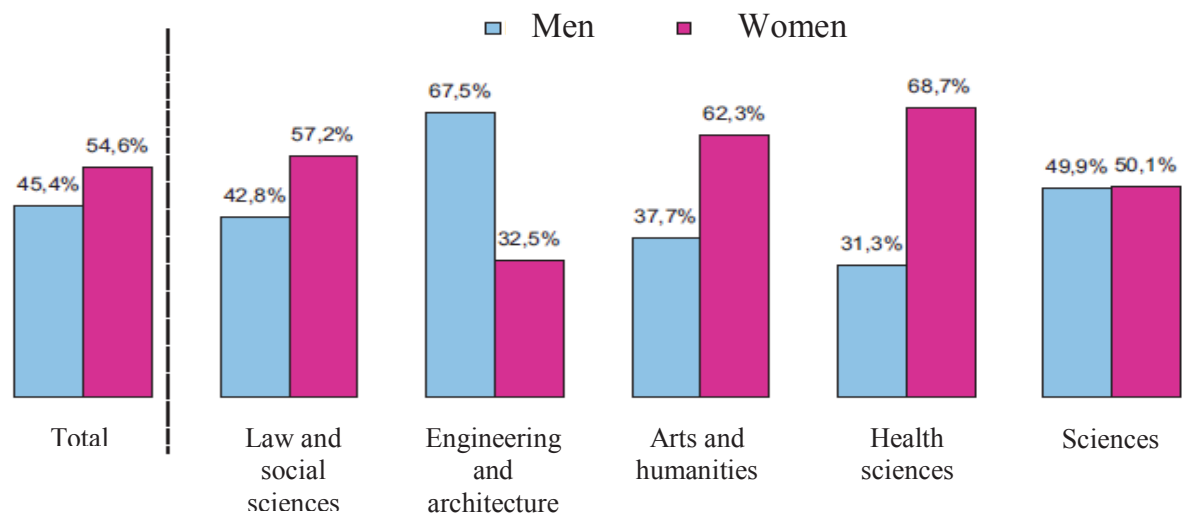

Figure 2. Master students distribution by education field and gender, 2011-12.

\subsubsection{Professors}

In Table.2, we show the distribution of the different academia positions, as well as the percentage of women in each category. With respect to the categories of professors who have a permanent position (with tenure) at the public universities, they are ordered in Table. 2 from the highest position (Full professor of university) to the lowest position (Professor of university schools).

We see that these percentages are much lower than for female students (Table1). In addition, the higher the position is in the rank of professors, the smaller the women representation is. This tendency can be also observed in Fig. 3, where the women scientific career is represented.

Table 2. Teaching and research faculty members in universities, indicating women percentage, 2010-11.

\begin{tabular}{|l|c|c|}
\hline & Total & \% of women \\
\hline Total & $\mathbf{1 1 5 . 2 1 8}$ & $\mathbf{3 8 , 1 \%}$ \\
\hline Public Universities & $\mathbf{1 0 4 . 7 5 6}$ & $\mathbf{3 7 , 8 \%}$ \\
\hline Government employees (civil servents) & 49.468 & $34,7 \%$ \\
\hline$\bullet \quad$ Full professor of university & 10.285 & $18,4 \%$ \\
\hline$\bullet \quad$ Professor of university & 30.082 & $38,9 \%$ \\
\hline$\bullet \quad$ Full professor of university schools & 1.378 & $29,4 \%$ \\
\hline$\bullet \quad$ Professor of university schools & 7.532 & $41,4 \%$ \\
\hline$\bullet \quad$ Other government employees & 191 & $30,9 \%$ \\
\hline Professor emeritus & 1.066 & $30,4 \%$ \\
\hline Own centers contracted employees & 49.797 & $40,3 \%$ \\
\hline Affiliated centers contracted employees & 4.425 & $45,2 \%$ \\
\hline Private Universities & $\mathbf{1 0 . 4 6 2}$ & $\mathbf{4 1 , 3 \%}$ \\
\hline Own centers contracted employees & 10.098 & $41,2 \%$ \\
\hline Affiliated centers contracted employees & 364 & $44,0 \%$ \\
\hline
\end{tabular}


The percentage of total women as faculty members of Public Universities is $37,8 \%$, but in the highest position (Full professor of university) the percentage of female professors decreases to $18,4 \%$ (Table2).

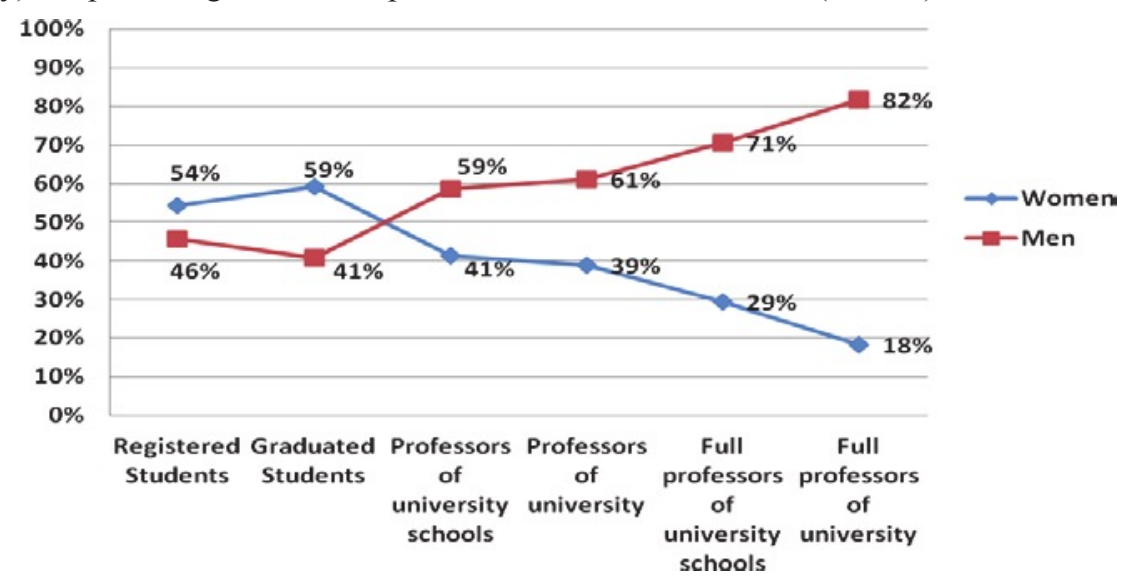

Figure 3. Women scientific career, 2010-11.

\subsection{Universitat Autònoma de Barcelona: physics degree}

Concerning the representation of female students in the physics degree, we have focused on the Universitat Autònoma de Barcelona (UAB). This academic year 2012-2013, the percentage of female students over the total registered students is $20,4 \%$. This value is much smaller than the representation of women in science majors $(53,6 \%$, see Fig. 1). This percentage of female students in the physics degree in our university has been without appreciable changes since 1994, as Fig.4 shows. The figures are similar in the degree of physics in other Spanish universities.

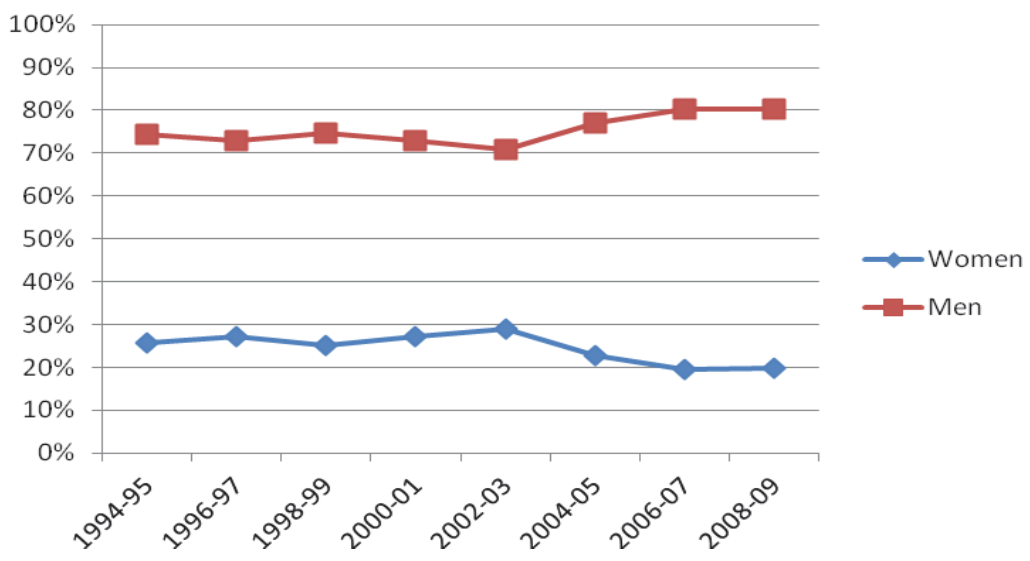

Figure 4. Evolution of women students registered in the physics degree at the Universitat Autònoma de Barcelona.

Since 2005, the UAB has an Observatory for Equality, a university organization created by the Governing Council of the Universitat Autònoma de Barcelona as a specialist support for the design and evaluation of equality policies. This organization is dedicated to the study and diagnosis of sexism at the university, of the situation of disabled people at the $\mathrm{UAB}$ and social and economic inequality. As well as, the creation of proposals for action aimed at correcting inequalities in these three fields.

\section{MENTORING PROGRAMS}

On the low number of women in physics and engineering, two moments in the women career are known to be crucial: First, at the end of the mandatory education and when girls are deciding their higher education and second, when they are finishing their majors or after their graduate studies, when the students will consider a professional or researcher career. 
Actually, the advisor guides to the graduate student, helping with the election of the professional career and transferring his or her knowledge [11].

We consider that during this second moment a mentoring program can be helpful. In general, these kinds of programs do not exist in the Spanish universities, although in other countries like in the US they are already integrated into the university society.

However, three years ago there was a pioneer mentoring project in Catalonia [12]. The program was promoted by the government of Catalonia, to promote the women career in science and technology. The project was addressed to 50 women in the scientific and technologist field, including the two authors of this paper. There were 25 pairs of mentor (prominent women working in science, technology, engineering in the university or a private company) - mentee (graduate student or young researcher). The mentoring process entails a personal exchange of knowledge and experiences between mentor and mentee, creating a reciprocal relationship with benefits for both. The participants were satisfied by the results achieved during this mentoring program. This project was stopped after that edition.

\section{PROJECTS OF THE OPTICAL PROFESSIONAL SOCIETIES}

The different international professional societies in physics and optics have their own groups focused on women in science. For instance: SPIE (the International Society for Optics and Photonics) [13], OSA (the Optical Society) [14], APS (American Physical Society) [15] and IUPAP (International Union for Pure and Applied Physics) [16].

SPIE Women in Optics promotes personal and professional growth for women through community building, networking opportunities and encouraging young women to choose optics as a career.

Minorities and Women in OSA (MWOSA) is dedicated to providing focused educational and networking opportunities, career support, grant information and related services to minorities and women in optics and photonics.

APS through the Committee on the Status of Women in Physics (CSWP), is committed to encouraging the recruitment, retention, and career development of women physicists at all levels.

The IUPAP working group on Women in Physics is dedicated to survey the situation for women in physics in IUPAP member countries. To analyze and report the data collected along with suggestions on how to improve the situation. To suggest ways that women can become more involved in IUPAP, including the Liaison Committees, the Commissions, the Council, and the General Assemblies.

We give here some figures and facts from SPIE. Women members currently make up $15 \%$ of SPIE membership. This can give an idea of the representation of female professionals in the fields of optics and photonics. Women make up more than $20 \%$ of the membership of SPIE Standing Committees; four of these 17 governance committees were chaired by women in both 2012 and 2013.

The program Women in Optics in SPIE makes several actions.

There is a SPIE WiO web page that features 14 video interviews with women speaking on both technical and personal development topics. The Women in Optics Planner is published yearly and 4,000 copies of it are distributed each year to school programs, by individual request, and at SPIE events. Although published yearly, SPIE has expanded the WiO planner to include 18 months so that its useful life is extended. 30 women were profiled for the 2013 edition. These monthly planners feature interviews with women in leading positions in optics and photonics industry, government, and academia.

In [17], Thomas comments from the stories of WiO planner 2013 that "Most people deal with obstacles when starting out in their careers. Since these women have stood their ground and moved forward despite such obstacles, more doors have been opened for women in science. The stories they share show that while the gender gap has narrowed, it has by no means closed. Another common thread in these stories is the importance of networking. Much of the advice found in the planner touches on learning from others, particularly those who have chosen a similar path".

SPIE sponsors $\mathrm{WiO}$ gatherings, ranging from featured speakers combined with receptions, to networking lunches, at 6-8 SPIE events each year. At Photonics West 2013 the WiO event was entitled: What Works for You: A Mentoring Panel for Women in Science and Technology, chaired by Michelle Xu, UC Berkeley, with five women panelists from different age groups and backgrounds. Optics and Photonics Symposium in August 2013 will feature a presentation: Finding the Right Fit: From Atmospheric Scientist to Educating the Next Generation of Scientists Worldwide, by Kathy Perkins, Director, PhET Interactive Simulations, University of Colorado Boulder.

In the professional societies there are several parameters that indicate the recognition of the work done by the researchers. We describe here the numbers of members upgraded to Fellow member category. With the data from SPIE there are 52 women fellows (7\%), out of 717 total fellows. To put it in perspective, $2 \%$ of the women members are fellows, compared to $5 \%$ of male members who are fellows. 


\section{FINAL COMMENTS}

If we compare the above results with the data in Europe, we can add the following: the data from the European Commission in 2010 show that the women make up 59\% of all graduates, $46 \%$ of $\mathrm{PhD}$ graduates, and progressively lower proportions of academic staff, down to $20 \%$ of grade A (equivalent to Full professors in most countries) across all subjects in the EU-27. Female researchers are more likely to be found in higher education or government sectors than in business enterprise, with only $19 \%$ in the latter sector (from a study of 2009). Women remain underrepresented on boards, too. The report in [18] advocates the use of proactive policies to promote gender equality because the data along the last years show little evidence that the gap will be closed by the action of time alone.

The actions that the community may do to correct the inequity of women in the professional careers in physics and in optics should be addressed to remove all the differences in resources and opportunities that the women may face.

If the society wants to increase the number of female students in physics and engineering, some actions for attracting more girls for pursuing these majors could be organized at the secondary schools. It is important to correct the image that these fields are male dominated by showing the existence of women working in these fields. An international interest on this issue exists and some countries organize specific actions (see for instance [19] in Spain and [20] in Germany).

\section{ACKNOWLEDGMENTS}

We acknowledge financial support from the Spanish Ministerio de Economia y Competitividad (FIS2012-39158-C0201). We would like to thank Ms. June Thompson for providing us with the SPIE data.

\section{REFERENCES}

[1] Sax, L.J., [The gender gap in college: maximizing the developmental potential of women and men], JosseyBass, A Wiley Imprint, San Francisco (2008).

[2] European Comission, "She figures 2012. Gender in research and innovation. Statistics and Indicators," 2012, http://ec.europa.eu/research/science-society/document_library/pdf_06/she-figures-2012 en.pdf.

[3] Feder, T. "Women, and some men, ask why women don't flock to Physics," Physics Today 55(5), 24 (2002).

[4] Feder, T. "Women unite to improve Physics culture," Physics Today 58(8), 29 (2005).

[5] "Global Survey of Physicists," http://www.aipsurveys.org/global.

[6] Ivie, R., Tesfaye, C., "The Global Survey of Physicists: A collaborative effort illuminates the situation of women in physics," 2011, http://www.aip.org/statistics/trends/highlite/women/global.pdf.

[7] Ivie, R., Tesfaye, C. L., "Women in physics: A tale of limits," Physics Today 65(2), 47 (2012).

[8] López-Sancho, M.P., Carreras, C., Chevalier, M., Campabadal, F., Yzuel, M.J., "Status of Women in Physics in Spain, 2011," AIP Conference Proc. 1517, 152-153 (2013).

[9] Ministerio de Educación, Cultura y Deporte, "Datos y cifras del sistema universitario español. Curso 20122013," 2012, http://www.mecd.gob.es/prensa-mecd/dms/mecd/prensa-mecd/actualidad/2013/01/20130118datos-univer/2012-2013-datos-cifras.pdf

[10] Vidal, J., Lizana, A., Peinado, A., Also, E., Lopez, D., Nicolas, J., Campos, J., and Yzuel, M.J., “Training Physics degree students in a research optics laboratory", Proc. ETOP, page ETA6 (2009).

[11]Dainty, J. C., "President's message," Optics \& Photonics News 22 (6), 4 (2011).

[12] "Ariadna, mentoring program", 2010, http://www20.gencat.cat/portal/site/empresaiocupacio/menuitem.32aac87fcae8e050a6740d63b0c0e1a0/?vgnext oid=ddc7604d1b9af1 10 VgnVCM1000000b0c1e0aRCRD\&vgnextchannel=ddc7604d1b9af110 VgnVCM10000 00b0c1e0aRCRD\&vgnextfmt=default.

[13] http://spie.org/x1845.xml

[14] http://www.osa.org/en-us/membership/grants_recognitions_special_services/mwosa/

[15] http://www.aps.org/programs/women/

[16] http://www.iupap.org/wg/wip/

[17] Thomas, K, "Career Advice. SPIE Women in Optics are making a difference," SPIE Professional 8(1), 10-11 (2013)

[18] Nicola, "She figures 2012 - Is progress being made?", 2013, http://sciencecampaign.org.uk/?p=12544.

[19] http://www.girls-day.es/

[20] http://www.girls-day.de/ 